\title{
The role of $d s b A$ in colonization of the wheat rhizosphere by Pseudomonas fluorescens Q8r1-96
}

\author{
Olga V. Mavrodi, ${ }^{1}$ Dmitri V. Mavrodi, ${ }^{1}$ Amanda A. Park, ${ }^{2}$ David M. Weller ${ }^{2}$ \\ and Linda S. Thomashow ${ }^{1,2}$
}

Correspondence

Linda S. Thomashow

thomasho@mail.wsu.edu

Received 27 September 2005

Revised 16 November 2005

Accepted 25 November 2005
Department of Plant Pathology ${ }^{1}$ and USDA-ARS, Root Disease and Biological Control
Research Unit ${ }^{2}$, Washington State University, Pullman, WA, USA
Certain well-conserved genes in fluorescent Pseudomonas spp. are involved in pathogenic interactions between the bacteria and evolutionarily diverse hosts including plants, insects and vertebrate animals. One such gene, $d s b A$, encodes a periplasmic disulfide-bond-forming enzyme implicated in the biogenesis of exported proteins and cell surface structures. This study focused on the role of $d s b A$ in Pseudomonas fluorescens Q8r1-96, a biological control strain that produces the antibiotic 2,4-diacetylphloroglucinol (2,4-DAPG) and is known for its exceptional ability to colonize the roots of wheat and pea. The deduced DsbA protein from Q8r1-96 is similar to other predicted thiol: disulfide interchange proteins and contains a conserved DsbA catalytic site, a pattern associated with the thioredoxin family active site, and a signal peptide and cleavage site. A $d s b A$ mutant of Q8r1-96 exhibited decreased motility and fluorescence, and altered colony morphology; however, it produced more 2,4-DAPG and total phloroglucinol-related compounds and was more inhibitory in vitro to the fungal root pathogen Gaeumannomyces graminis var. tritici than was the parental strain. When introduced separately into a natural soil, Q8r1-96 and the $d s b A$ mutant did not differ in their ability to colonize the rhizosphere of wheat in greenhouse experiments lasting 12 weeks. However, when the two strains were co-inoculated, the parental strain consistently out-competed the $d s b A$ mutant. It was concluded that $d s b A$ does not contribute to the exceptional rhizosphere competence of Q8r1-96, although the $d s b A$ mutation reduces competitiveness when the mutant competes with the parental strain in the same niche in the rhizosphere. The results also suggest that exoenzymes and multimeric cell surface structures are unlikely to have a critical role in root colonization by this strain.

\section{INTRODUCTION}

Plant growth-promoting rhizobacteria (PGPR) are rootassociated bacteria from many different genera that can increase the growth of plants when applied to soil, seeds or vegetatively propagated plant parts (Weller \& Thomashow, 1994). Despite their potential economic and environmental benefits, efforts to exploit PGPR commercially as biopesticides, biofertilizers or phytostimulants have been restricted by inconsistent results caused in part by poor root colonization. Most introduced rhizobacteria establish high rhizosphere population densities initially, but then the population declines with time and distance from the inoculum source. Densities of introduced rhizobacteria also vary from root

\footnotetext{
Abbreviations: 2,4-DAPG, 2,4-diacetylphloroglucinol; MAPG, monoacetylphloroglucinol; PGPR, plant growth-promoting rhizobacteria.

The GenBank/EMBL/DDBJ accession number for the $d s b A$ sequence of $P$. fluorescens Q8r1-96 reported in this paper is AY171618.
}

to root and plant to plant, leaving some plants or roots unprotected (Bull et al., 1991; Weller \& Thomashow, 1994; Weller, 1988).

Root colonization and ecological fitness of PGPR is a complex phenotype affected by many different traits and by environmental factors (Lugtenberg et al., 2001; Weller \& Thomashow, 1994). Among the root colonization determinants shown to contribute to the PGPR-plant root interaction are flagella (de Weger et al., 1987), fimbriae (Camacho Carvajal, 2000), synthesis of the O-antigen of lipopolysaccharide (Dekkers et al., 1998a), and a site-specific sss recombinase thought to play a role in regulating the biosynthesis of cell surface components (Dekkers et al., 1998b, 2000). Other root-colonization traits are associated with the ability to synthesize essential compounds (Dekkers et al., 1998c; Simons et al., 1997) and sequester nutrients or tolerate physical stresses (Lugtenberg et al., 2001). In addition, the discovery of type III secretion genes in many PGPR strains 
(Preston et al., 2001; Rainey, 1999; Mazurier et al., 2004; Rezzonico et al., 2004) suggests that at least some saprophytic rhizobacteria may have a more sophisticated relationship with host tissues than previously was recognized. Evidence of common determinants involved in the pathogenicity of bacteria such as Pseudomonas aeruginosa to plants and animals (Lugtenberg et al., 2001; Rahme et al., 2000) further supports this idea.

Fluorescent Pseudomonas spp. that produce the polyketide antibiotic 2,4-diacetylphloroglucinol (2,4-DAPG) are highly effective biocontrol agents of soilborne pathogens (Duffy \& Défago, 1997; Keel et al., 1992; Tamietti et al., 1993). Strains of most of the 22 genotypes of DAPG producers described to date are phenotypically very similar (McSpadden Gardener et al., 2000; O. V. Mavrodi et al., 2001), but they differ considerably in their ability to colonize the rhizosphere of certain crop species (Landa et al., 2002b, 2003; Raaijmakers \& Weller, 2001). In particular, D-genotype isolates are highly aggressive colonists of wheat and pea and have an affinity for these crops as compared to most other genotypes. Dgenotype isolates collected from different locations all display the ability to establish and maintain a large population size in the rhizosphere, even when introduced at densities of only 10-100 c.f.u. (g soil) ${ }^{-1}$ (Landa et al., 2002b, 2003; Raaijmakers \& Weller, 2001). Our efforts to understand the molecular basis for the unique root-colonizing ability of P. fluorescens Q8r1-96, the most completely described of the D-genotype strains (Landa et al., 2002b; Raaijmakers \& Weller, 2001), have focused in part on genes common to saprophytic and pathogenic bacteria and implicated in pathogenesis. Because such genes have a role in an intimate and active molecular dialogue between bacteria and their hosts, we hypothesize that they also may provide insight into the unique affinity of D-genotype strains for their plant hosts. Among these genes is $d s b A$, which encodes a periplasmic protein that catalyses disulfide bond formation in exported proteins of Gram-negative bacteria (Bardwell et al., 1991). While the number and identity of all of the proteins acted upon by DsbA is not known, it has been shown to be essential for the biogenesis of virulence factors and multimeric structures on the bacterial surface including fimbriae and components of the type III secretion apparatus. DsbA has been implicated in the interactions of $P$. aeruginosa and Pseudomonas syringae pv. tomato with Arabidopsis (Rahme et al., 1997; Kloek et al., 2000), and it is involved in the assembly of a functional type III secretion apparatus in Shigella flexneri (Watarai et al., 1995) and Yersinia pestis (Jackson \& Plano, 1999); in secretion of pectate lyases and cellulase in Erwinia chrysanthemi (Shevchik et al., 1995); in formation of toxin-coregulated pili in Vibrio chlolerae $(\mathrm{Hu}$ et al., 1997); and in stabilization of periplasmic lipase in $P$. aeruginosa (Urban et al., 2001). In this study we identified and characterized the $d s b A$ orthologue in $P$. fluorescens Q8r1-96 and evaluated its role in root colonization and the competitiveness of this strain in the wheat rhizosphere. We show that $d s b A$ does not contribute to the exceptional rhizosphere competence of Q8r1-96, and that root colonization by a $d s b A$ mutant of Q8r1-96 is reduced when the mutant is in competition with the wild-type, but not in the presence of indigenous rhizosphere microflora.

\section{METHODS}

Bacterial strains, plasmids and growth conditions. The bacterial strains and plasmids used in this study are described in Table 1. A rifampicin-resistant derivative of Q8r1-96 (Landa et al., 2002b) was used for gene replacement mutagenesis, while Q8r1-96Gm, a rifampicin-resistant derivative tagged with mini-Tn7-gfp2 (Validov et al., 2005) was used in competitive colonization experiments. Escherichia coli TOP 10 (Invitrogen) was used for cloning experiments and E. coli S17-1( $\lambda$-pir) was the donor strain in biparental matings with $P$. fluorescens Q8r1-96. P. fluorescens and E. coli strains were grown at $28^{\circ} \mathrm{C}$ and $37^{\circ} \mathrm{C}$, respectively, in Luria-Bertani (LB) medium (Ausubel et al., 1995), Pseudomonas agar F (PsF) (Difco), Pseudomonas agar P (PsP) (Difco) or King's medium B (KMB) (King et al., 1954). Densities of total culturable heterotrophic bacteria (TCB) were determined in one-tenth-strength Tryptic Soy (TS) broth (Difco). Antibiotic supplements (Sigma) were used at the following concentrations: ampicillin, 100 or $40 \mu \mathrm{g} \mathrm{ml}^{-1}$; rifampicin, 100 or $90 \mu \mathrm{g} \mathrm{ml}^{-1}$; tetracycline, 10 or $12.5 \mu \mathrm{g} \mathrm{ml}^{-1}$; gentamicin, $2 \mu \mathrm{g} \mathrm{ml}^{-1}$; cycloheximide, $100 \mu \mathrm{g} \mathrm{ml}^{-1}$; chloramphenicol, 13 or $35 \mu \mathrm{g} \mathrm{ml}^{-1}$; and kanamycin, 25 or $50 \mu \mathrm{g} \mathrm{ml}^{-1}$.

DNA manipulations. Standard methods were used for plasmid isolation, restriction enzyme digestion, agarose gel electrophoresis, ligation and transformation (Ausubel et al., 1995). PCR amplification was carried out with Taq (Promega) or KOD Hot Start (Novagen) DNA polymerase. The oligonucleotide primers listed in Table 2 were developed with Oligo 6.65 Software (Molecular Biology Insights).

Identification of $\boldsymbol{d s b A}$ in $\boldsymbol{P}$. fluorescens Q8r1-96. An arrayed genomic library of P. fluorescens Q8r1-96 (Mavrodi, 2004), constructed in the broad-host-range vector pCPP47 (Bauer \& Collmer, 1997), was screened by colony hybridization (Birren et al., 1999) with a ${ }^{32} \mathrm{P}$-labelled $d s b A$-specific probe amplified by PCR from DNA of P. fluorescens SBW25 with primers DSBA_UP and DSBA_LOW (Table 2), which were developed from the $d s b A$ sequence of strain SBW25 (http://www.sanger.ac.uk/Projects/P_fluorescens/). Cycling included a 2 min denaturation at $94^{\circ} \mathrm{C}$, followed by 29 cycles of $94{ }^{\circ} \mathrm{C}$ for $15 \mathrm{~s}, 61^{\circ} \mathrm{C}$ for $30 \mathrm{~s}$, and $68^{\circ} \mathrm{C}$ for $1.2 \mathrm{~min}$, and a final extension at $68^{\circ} \mathrm{C}$ for $5 \mathrm{~min}$. To localize $d s b A$ within positive clones, cosmid DNA digested with EcoRI, KpnI and SacI was blotted and hybridized with a biotinylated $d s b A$ probe.

Transposon mutagenesis, shotgun sequencing and sequence analysis. To tag $d s b A$ and adjacent regions of cosmid clones for DNA sequence analysis, purified cosmid DNA was mutagenized in vitro by using the EZ::TN $<$ Kan-2 $>$ transposition system (Epicentre Technologies). Transposon insertions within DNA fragments containing $d s b A$ were identified by restriction mapping and shotgun-sequenced by using an ABI PRISM BigDye Terminator Cycle Sequencing Ready Reaction Kit (Applied Biosystems). Sequence data were compiled and analysed with OMIGA 2.0 software (Accelrys). Database searches for similar protein sequences were performed using NCBI's BLAST network service. Searches against PROSITE, Profile, HAMAP and Pfam collections of protein motifs and domains were carried out using the MyHits Internet engine (Pagni et al., 2004), and signal peptide cleavage sites were predicted with SignalP v. 3.0 (Bendtsen et al., 2004).

Allelic replacement in Q8r1-96. The $d s b A$ gene containing EZ: $: \mathrm{TN}^{\mathrm{TM}}<$ Kan-2 $>$ was amplified with DSBA_UP and DSBA_LOW primers by using KOD Hot Start DNA polymerase. The cycling programme included a 2 min denaturation at $94{ }^{\circ} \mathrm{C}$ 
Table 1. Bacterial strains and plasmids

\begin{tabular}{|c|c|c|}
\hline Strain/plasmid & Relevant characteristics ${ }^{\star}$ & Reference of origin \\
\hline \multicolumn{3}{|l|}{ P. fluorescens } \\
\hline Q8r1-96 & $\mathrm{DAPG}^{+}$Rif $^{\mathrm{r}}$ & Landa et al. (2002) \\
\hline Q8r1-96dsbA & $d s b A:: \mathrm{TN}<\mathrm{Kan} 2>; \mathrm{DAPG}^{+} \operatorname{Rif}^{\mathrm{r}} \operatorname{Kan}^{\mathrm{r}}$ & This study \\
\hline \multicolumn{3}{|l|}{ E. coli } \\
\hline \multicolumn{3}{|l|}{ Plasmids } \\
\hline рСРР47 & Broad-host-range cosmid derived from pCPP34, tandem $\cos ^{+}$, par $^{+}, \mathrm{Tet}^{\mathrm{r}}$ & Bauer \& Collmer (1997) \\
\hline pMOB3 & $\operatorname{Kan}^{\mathrm{r}} \mathrm{Cam}^{\mathrm{r}}$, oriT $s a c B$ & Schweizer (1992) \\
\hline pNOT19 & ColE1 oriV, Amp ${ }^{\mathrm{r}}$; accessory plasmid & Schweizer (1992) \\
\hline pME6010-ccdB & $\begin{array}{l}\text { Gateway destination vector derived from pME6010 with } c c d B \text {-Cam }{ }^{\mathrm{r}} \text { cassette } \\
\text { flanked by attR1 and } a t t R 2\end{array}$ & This study \\
\hline pMK2010 & $\begin{array}{l}\text { Gateway entry vector; ColE1 oriV, oriT } T_{\mathrm{RP} 4}, \mathrm{Kan}^{\mathrm{r}}, c c d B \text {-Cam }{ }^{\mathrm{r}} \text { cassette flanked } \\
\text { by attP1 and attP2 }\end{array}$ & House et al. (2004) \\
\hline pMK2010dsbA & pMK2010 containing the $0.67 \mathrm{~kb}$ DNA fragment with $d s b A$ & This study \\
\hline pME6010dsbA & pME6010 containing the $0.67 \mathrm{~kb}$ DNA fragment with $d s b A$ & This study \\
\hline
\end{tabular}

${ }^{\star}$ DAPG, strain produces 2,4-diacetylphloroglucinol; Rif ${ }^{\mathrm{r}}$, rifampicin resistance; $\mathrm{Gm}^{\mathrm{r}}$, gentamicin resistance; Amp ${ }^{\mathrm{r}}$, ampicillin resistance; Tet ${ }^{\mathrm{r}}$, tetracycline resistance; $\mathrm{Kan}^{\mathrm{r}}$, kanamycin resistance; $\mathrm{Cam}^{\mathrm{r}}$, chloramphenicol resistance.

followed by 29 cycles of $94{ }^{\circ} \mathrm{C}$ for $15 \mathrm{~s}, 61^{\circ} \mathrm{C}$ for $30 \mathrm{~s}$ and $68^{\circ} \mathrm{C}$ for $1.2 \mathrm{~min}$, and a final extension at $68^{\circ} \mathrm{C}$ for $5 \mathrm{~min}$. The amplification product was cloned into the SmaI site of pNOT19 (Schweizer, 1992) and the plasmid was then digested with NotI and ligated with a $5 \mathrm{~kb}$ NotI fragment of the pMOB3 cassette (Schweizer, 1992) containing $s a c B$ and cat genes. The resultant pNOT19-dsbA-Kan-MOB plasmid was electroporated into E. coli S17-1( $\lambda$-pir), selected on LB medium supplemented with chloramphenicol and kanamycin, and mobilized by mating into $P$. fluorescens Q8r1-96Rif ${ }^{\mathrm{r}}$. Mutant clones were selected on LB supplemented with rifampicin, kanamycin and $5 \%$ sucrose. Positive clones were screened for the absence of $s a c B$, bla and cat genes by PCR with primers SAC1 and SAC2, BLA1 and BLA2 (D. V. Mavrodi et al., 2001) and Cm_UP and Cm_LOW (Table 2), respectively. Primers KAN_UP and KAN_LOW (Table 2) and DSBA_UP and DSBA_LOW were used to detect the kanamycin resistance gene in $d s b A$ mutants and to confirm the absence of the wild-type $d s b A$ allele. All mutant clones were isogenic and one clone was chosen for further experiments.

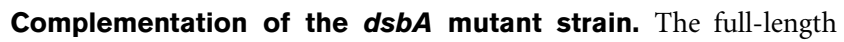
$d s b A$ gene was cloned into the stable broad-host-range plasmid pME6010 (Heeb et al., 2000) using Gateway Technology (Invitrogen) in conjuction with nested PCR as described by House et al. (2004). Briefly, $d s b A$ was amplified with primers dsbAF-dsbAR (Table 2) and $a t t B$ sequences were introduced by reamplification with primers 2F-2R (House et al., 2004). The resultant PCR fragment was cloned into the entry plasmid pMK2010 (House et al., 2004) with BP Clonase II (Invitrogen), single-pass sequenced to confirm its integrity, and

Table 2. Oligonucleotides

\begin{tabular}{|ll|}
\hline Primer name & \multicolumn{1}{c|}{ Sequence $^{\star}$} \\
\hline DSBA_UP & $5^{\prime}$-GAT ACC AAG CCG ATG CAG A-3' \\
DSBA_LOW & $5^{\prime}$-GGA CAT GAC ATG ATG CTC GT-3' \\
KAN_UP & $5^{\prime}$-TGG CAA GAT CCT GGT ATC GGT-3' \\
KAN_LOW & $5^{\prime}$-GAA ACA TGG CAA AGG TAG CGT-3' \\
Cm_UP & $5^{\prime}$-ATC CCA ATG GCA TCG TAA AGA-3' \\
Cm_LOW & $5^{\prime}$-AAG CAT TCT GCC GAC AT-3' \\
dsbAF & $5^{\prime}$-GGA GGC TCT TCA ATG CGT AAT CTG ATC ATC AG-3' \\
dsbAR & $5^{\prime}$-AGC TGG GTT CTA GTT GGC AGC AGC CTT GGT GG-3' \\
\hline
\end{tabular}

*Oligonucleotides were designed by using Oligo 6.65 Primer Analysis Software. 
transferred with LR Clonase II (Invitrogen) into pME6010, which had been converted into a Gateway destination vector by introduction of a $c c d B$ - and attR-containing cassette (Invitrogen) (Table 1). The resultant plasmid was electroporated into Q8r1-96dsbA as described by Enderle \& Farwell (1998).

Phenotypic analysis in vitro. For motility assays, colony diameter was measured 24, 48 and $72 \mathrm{~h}$ after inoculation. Exoprotease production was assessed on skim milk agar (Sacherer et al., 1994) as a cleared zone surrounding bacterial growth after incubation for 48 and $72 \mathrm{~h}$ at $28^{\circ} \mathrm{C}$. Hydrogen cyanide production was monitored by using cyanide detection paper placed on Petri dish lids (Bakker \& Schippers, 1987). Observations were made every $24 \mathrm{~h}$ and all cultures were screened twice. Polysaccharide production was scored after 3 days of growth on PsP agar on a scale of $0-5$, where 0 indicates a non-mucoid isolate and 5 indicates a moderately mucoid culture. Siderophore production was determined by measuring orange haloes after 2 days of growth at $28^{\circ} \mathrm{C}$ on CAS agar (Schwyn $\&$ Neilands, 1987). Experiments were repeated twice with four replicates per strain. Inhibition of G. graminis var. tritici by $P$. fluorescens Q81-96Gm and its mutants was assayed on PsF agar as described earlier (McSpadden Gardener \& Weller, 2001). Assays were repeated twice, with six replicates per strain. Carbon substrate and nitrogen utilization profiles were generated by using Biolog SF-N2 and PM3 MicroPlates, respectively. Four independent repetitions were performed with each strain. M9 minimal media supplemented with $0.4 \% \mathrm{D}$-galactose as a carbon source or with $10 \mathrm{mM}$ of nitrogen sources was used for validation of Biolog assays. Phloroglucinol compounds were extracted with ethyl acetate from bacterial cultures grown for $48 \mathrm{~h}$ at $27^{\circ} \mathrm{C}$ in PsF broth. Extracts were fractionated on a Waters NOVA-PAK $\mathrm{C}_{18}$ Radial-PAK cartridge $(4 \mu \mathrm{m}, 8 \times 100 \mathrm{~mm})$ as described earlier (Bonsall et al., 1997). Two independent experiments with five replications were performed.

Rhizosphere colonization assays. Bacterial inocula of Q8r1$96 d s b A$ and Q8r1-96Gm, a gentamicin-resistant derivative of the parental strain (Validov et al., 2005), were prepared to give approx. $1 \times 10^{4}$ c.f.u. (g soil) $)^{-1}$ when strains were introduced alone or $\sim 0 \cdot 5 \times 10^{4}$ c.f.u. (g soil) $)^{-1}$ in $1: 1$ mixtures. Actual strain densities were determined by assaying the inoculated soil as described by Landa et al. (2002a). The control treatment consisted of soil amended with a $1 \%$ methylcellulose suspension. Seeds of pre-germinated spring wheat (Triticum aestivum L.) cv. Penawawa were sown in square pots $(6.5 \mathrm{~cm}$ high $\times 7 \mathrm{~cm}$ wide) filled with $200 \mathrm{~g}$ Quincy virgin soil inoculated with one or both bacterial strains. Seedlings were grown for 2 weeks (one cycle) in a controlled-environment chamber and the population size of the introduced bacteria was determined after each of six cycles (Landa et al., 2003). Each treatment was replicated six times, with one pot serving as replicate, and the experiment was conducted twice. After the sixth cycle, soil from pots of the same treatment was decanted into plastic bags and stored at $20^{\circ} \mathrm{C}$ for 10 weeks before again growing wheat for two cycles in order to assess the ability of the strains to survive in the absence of roots.

Population densities of the introduced strains were determined by the dilution end-point method (McSpadden Gardener et al., 2001) as modified by Validov et al. (2005). Briefly, soil ( $0.5 \mathrm{~g})$ or root samples in $10 \mathrm{ml}$ sterile distilled water were vortexed, sonicated, serially diluted in 96-well microtitre plates pre-filled with sterile distilled water, and then each dilution was transferred to another plate containing one-thirdstrength KMB broth supplemented with rifampicin, cycloheximide, ampicillin and chloramphenicol $\left(1 / 3 \times \mathrm{KMB}^{+++}\right.$Rif) (McSpadden Gardener et al., 2001). After 3 days these cultures subsequently were replicated to fresh $1 / 3 \times \mathrm{KMB}^{+++}$Rif plates amended with kanamycin or gentamicin to distinguish between strains from mixed inoculations.
Bacterial growth was assessed after $72 \mathrm{~h}$ with an $\mathrm{OD}_{600} \geqslant 0 \cdot 07$ scored as positive (McSpadden Gardener et al., 2001). In some cases, results were verified by PCR.

Densities of total culturable heterotrophic bacteria were determined by the terminal dilution end point assay in one-tenth-strength TS broth supplemented with cycloheximide (McSpadden Gardener et al., 2001).

Data analysis. Treatments in competitive colonization experiments were arranged in a complete randomized design. Data were analysed with STATISTIX 8.0 software (Analytical Software). Population data were converted to $\log$ c.f.u. (g soil) ${ }^{-1}$ or fresh root weight. Differences in population densities among treatments were determined by standard analysis of variance, and mean comparisons among treatments were performed by using Fisher's protected least significant difference test $(P=0 \cdot 05)$ or by the Kruskal-Wallis test $(P=0 \cdot 05)$. Data from phenotypic analyses in vitro were compared by using a two-sample $t$ test or Wilcoxon rank sum test $(P=0 \cdot 05)$.

\section{RESULTS}

\section{Identification, cloning and characterization of the dsbA gene}

Clones containing the $d s b A$ gene from $P$. fluorescens Q8r1-96 were identified in an ordered genomic library of 1536 clones by colony hybridization with a $d s b A$-specific probe from $P$. fluorescens SBW25. An initial round of hybridization yielded eight positive clones, from which cosmid DNA was isolated, digested with restriction endonucleases EcoRI, KpnI or SacI, blotted, and again hybridized with a $d s b A$ probe in order to localize the gene. One clone, $3 \mathrm{~B} 12$, in which $d s b A$ mapped to a $4 \cdot 6 \mathrm{~kb} E c o \mathrm{RI}$ fragment, was then mutagenized in vitro with EZ:: $\mathrm{Tn}<\operatorname{Kan} 2>$. DNA from 200 kanamycin-resistant clones was digested with EcoRI and cosmids with shifts in the electrophoretic mobility of the target $4.6 \mathrm{~kb}$ fragment were sequenced with transposon-based primers.

The sequence data were assembled into a 2962 bp contig containing five potential open reading frames, one of which encoded a product similar to bacterial thiol: disulfide exchange proteins. This gene, designated $d s b A$, was preceded by a well-conserved ribosome-binding site, AGGAG, and encodes a predicted 213 aa protein of molecular mass 23080 $\mathrm{Da}$. The contig also contained two putative genes encoding precursors of cytochromes $c_{5}$ and $c_{4}$, and two genes for conserved hypothetical proteins, one of which was located immediately downstream of $d s b A$.

The deduced DsbA protein is highly similar to predicted thiol: disulfide interchange DsbA proteins from other pseudomonads, including $P$. fluorescens Pf0-1 (NCBI accession number ZP_00266803; $91 \%$ identity), P. syringae pv. syringae DC3000 (AA053886; $79 \%$ identity), Pseudomonas putida KT2440 (NP_742297; $77 \%$ identity), P. fluorescens Pf-5 (YP_257237; 74\% identity) and $P$. aeruginosa PAO1 (U84726; $72 \%$ identity). Among these, DsbA from $P$. aeruginosa $\mathrm{PAO} 1$ has been shown to have thiol: disulfide oxidoreductase activity in the same range as that of DsbA from E. coli (Urban et al., 2001). The consensus DsbA catalytic site, Cys-Pro-His-Cys (residues 56-60), a conserved 
PROSITE pattern associated with the thioredoxin family active site (residues 47-65), and a Pfam DsbA-like thioredoxin domain (residues 46-181) also are present in DsbA from $P$. fluorescens Q8r1-96. Results of SignalP-HMM (Bendtsen et al., 2004) predictions revealed a well-conserved signal peptide and a potential cleavage site between residues 22 and 23. In addition, based on analysis of the complete genome sequence of other pseudomonads, $P$. fluorescens Q8r1-96 has one copy of $d s b A$.

\section{Phenotypic effects of the $d s b A$ mutation}

The $d s b A$ gene of strain Q8r1-96 was mutated as described in Methods. The resulting mutant exhibited reduced motility, reduced fluorescence and changes in colony colour. Altered motility was most apparent on $0.3 \%$ agar, on which migration of the mutant was on average $2 \cdot 2$ and $2 \cdot 0$ times less than that of the wild-type after 24 and $48 \mathrm{~h}$, respectively (Table 3). Neither the mutant nor the wild-type exhibited swarming behaviour at higher agar concentrations.

P. fluorescens produces water-soluble siderophores that strongly bind ferric iron under iron-limiting conditions. Siderophore excretion as estimated on CAS agar was significantly reduced in the $d s b A$ mutant compared to wild-type Q8r1-96 (Table 3). Differences also were observed in the appearance of colonies of the parental and mutant strains: those of the $d s b A$ mutant were less mucoid on PsP agar (data not shown) than those of the wild-type. On LB medium supplemented with glucose, colonies of the $d s b A$ mutant were consistently orange-tan in colour whereas colonies of Q8r1-96 were greyish-brownish in dense areas and isolated colonies were beige with a darker centre.
As compared to Q8r1-96, the $d s b A$ mutant grew more slowly on D-galactose as a source of carbon and on D-serine as a source of nitrogen when grown in Biolog SF-N2 and PM3 MicroPlates. These differences were validated in studies conducted with appropriately supplemented cultures grown on M9 medium (data not shown).

The $d s b A$ mutant was not impaired in the accumulation of extracellular protease (Table 3 ) or the production of hydrogen cyanide (data not shown).

\section{Effect of the dsbA mutation on phloroglucinol production and inhibition of G. graminis var. tritici in vitro}

Both wild-type $P$. fluorescens Q8r1-96 and the $d s b A$ mutant produced 2,4-DAPG as well as monoacetylphloroglucinol (MAPG) and three other uncharacterized phloroglucinolrelated compounds (data not shown). Because MAPG is a precursor for 2,4-DAPG (Bangera \& Thomashow, 1999; Shanahan et al., 1992) and the uncharacterized phloroglucinols detected in these analyses may include condensation products of either or both compounds (R. F. Bonsall, O. V. Mavrodi, D. V. Mavrodi \& D. M. Weller, unpublished data), we quantified all three classes of phloroglucinol-related compounds (Table 3 ). The $d s b A$ mutant produced approximately $50 \%$ more 2,4-DAPG and total phloroglucinolrelated compounds than did wild-type Q8r1-96.

These data correlated with the results of fungal inhibition assays, which showed that the $d s b A$ mutant was more inhibitory in vitro to G. graminis var. tritici than was the wild-type. Calculated hyphal inhibition indices for the mutant and the

Table 3. Phenotypic effects of the $d s b A$ mutation in P. fluorescens Q8r1-96

\begin{tabular}{|c|c|c|}
\hline \multirow[t]{2}{*}{ Test } & \multicolumn{2}{|c|}{ Bacterial strain } \\
\hline & Q8r1-96 & Q8r1-96dsbA \\
\hline Siderophore production ${ }^{*}$ & $8 \cdot 5 \mathrm{a}$ & $6 \cdot 9 \mathrm{~b}$ \\
\hline Exoprotease production $\dagger$ & $6 \cdot 7 a ; 9 \cdot 8$ a & 6 a; 10 a \\
\hline Motility $\ddagger$ & $20 \cdot 2$ a; $32 \cdot 3$ a; 38.7 a & $9 \cdot 33 \mathrm{~b} ; 16.3 \mathrm{~b} ; 19 \cdot 3 \mathrm{~b}$ \\
\hline MAPG production $\S$ & $2 \cdot 1 \times 10^{6}$ a $(100 \%)$ & $3 \cdot 0 \times 10^{6}$ all $(140 \%)$ \\
\hline 2,4-DAPG production $\S$ & $9 \cdot 4 \times 10^{6}$ a $(100 \%)$ & $13 \cdot 9 \times 10^{6}$ a $(147 \cdot 5 \%)$ \\
\hline Total phloroglucinol-related compounds $\$$ & $12 \cdot 0 \times 10^{6} \mathrm{~b}(100 \%)$ & $17 \cdot 6 \times 10^{6}$ a $(146 \cdot 6 \%)$ \\
\hline
\end{tabular}

${ }^{\star}$ Siderophore production was determined by measuring orange haloes after 2 days growth at $28^{\circ} \mathrm{C}$ on CAS agar. Values are means of four replicate plates. Values followed by the same letter are not significantly different according to the two-sample $t$ test.

$\nmid$ Zone of casein degradation on milk agar plates in $\mathrm{mm}$, after 48 and $72 \mathrm{~h}$ bacterial growth, respectively. Values are means of three replicate plates. Values followed by the same letter are not significantly different according to the two-sample $t$ test.

\$Diameter of bacterial spread in mm on $0.3 \%$ LB. Mean values of six replicate plates after 24,48 and $72 \mathrm{~h}$ bacterial growth. Values followed by the same letter are not significantly different according to the twosample $t$ test.

$\$$ Peak area/OD. Values in parentheses represent percentages. Values are means of five replicate extractions. Values followed by the same letter are not significantly different according to the two-sample $t$ test or the IIWilcoxon rank sum test, $\alpha=0 \cdot 05$. 
wild-type strain at 4 days after inoculation were $0 \cdot 41$ and $0 \cdot 36$, respectively. After 6 and 7 days, inhibition indices were $0 \cdot 22$ and $0 \cdot 13$ for the mutant and $0 \cdot 16$ and 0.07 for the parental strain.

\section{Effect of the $d s b A$ mutation on rhizosphere colonization by Q8r1-96}

Rhizosphere colonization studies were conducted using Q8r1-96dsbA, which is kanamycin-resistant, and Q8r1$96 \mathrm{Gm}$, a gentamicin-resistant derivative tagged with miniTn7-gfp2 (Validov et al., 2005). This allowed the wild-type and mutant strains to be distinguished in mixed inoculation experiments. The growth kinetics of the wild-type and miniTn7-gfp2 tagged strains did not differ in $1 / 3 \times \mathrm{KMB}$ and MMP minimal media, and the growth rates of Q8r1-96Gm and the $d s b A$ mutant also were indistinguishable in LB medium and minimal M9 medium supplemented with glycerol (data not shown).

The rhizosphere competence of the $d s b A$ mutant was compared to that of Q8r1-96Gm in single and mixed (1:1 ratio) inoculation studies on roots of wheat grown in a natural Quincy virgin soil. Fig. 1 shows the population dynamics for the two strains in the rhizosphere during six 2 week growth cycles. The population densities established in the soil were similar for both strains at the beginning of each experiment (cycle 0 ). In both the individual and the mixed inoculations, population sizes of both strains had increased by four orders of magnitude after one cycle and then the densities slowly declined over the next five cycles.

When the strains were introduced separately, the population dynamics of Q8r1-96Gm and the $d s b A$ mutant did not differ consistently in the wheat rhizosphere. In experiment 1 , the population sizes of the two strains were comparable through cycle 4 , but in cycles 5 and 6 the population size of Q8r1$96 \mathrm{Gm}$ was significantly $(P=0.05)$ greater than that of the mutant (Fig. 1a). However, in experiment 2, the population sizes of the two strains did not differ in cycles 1,2, 4 and 6; the population size of Q8r1-96Gm was greater than that of the mutant in cycle 5; and the population size of the mutant was greater than that of the wild-type strain in cycle 3 (Fig. 1b).

When introduced together into the soil, the $d s b A$ mutant consistently colonized the wheat rhizosphere to a lesser extent than did Q8r1-96Gm. In experiment 1, the population sizes of both strains were similar throughout cycles 1,2 and 3, but the population size of Q8r1-96Gm was significantly greater than that of the mutant in cycles 4, 5 and 6 (Fig. 1a). These differences were consistent and occurred to a greater extent in experiment 2 , in which the population size of the mutant was significantly less than that of the wildtype in all cycles (Fig. 1b).

Population densities of total culturable aerobic bacteria in the wheat rhizosphere in all four bacterial treatments and in
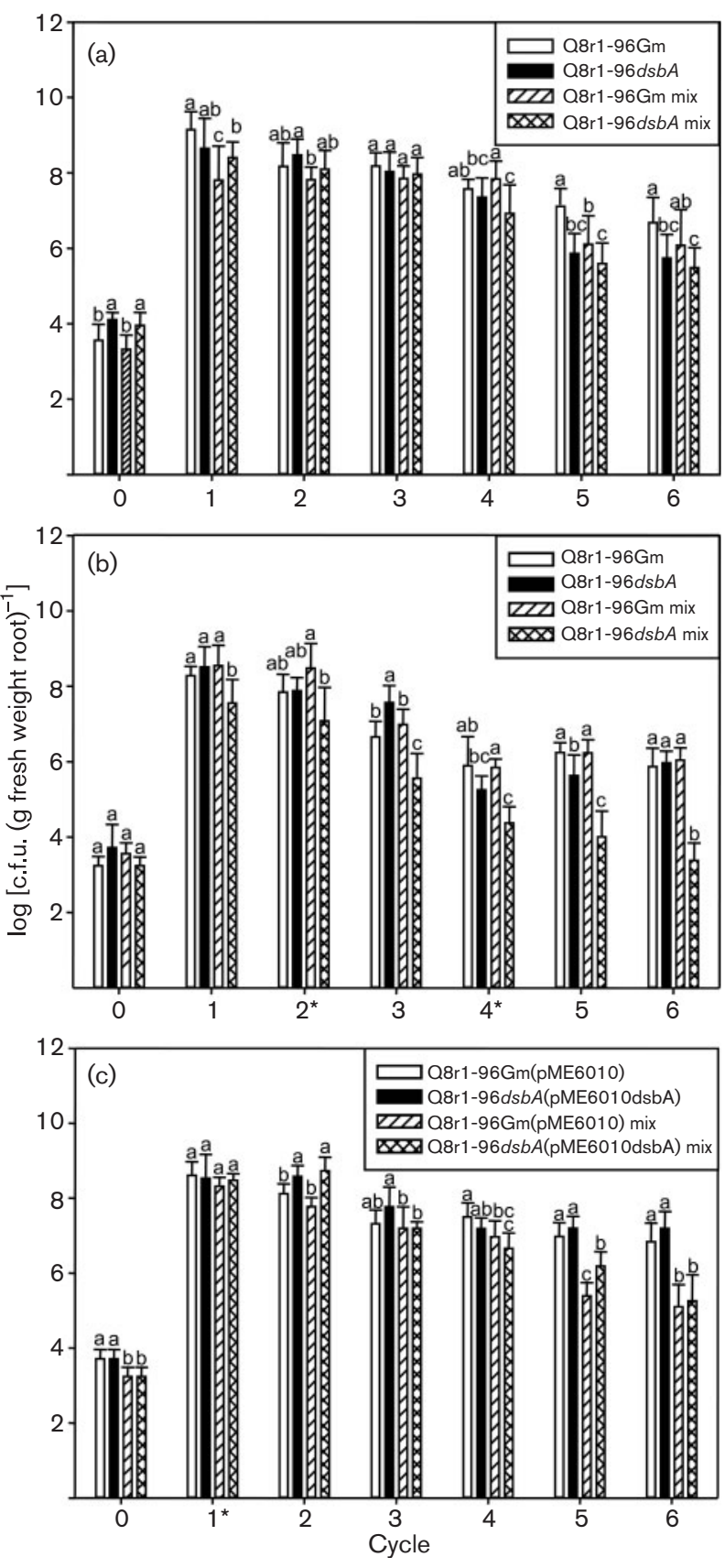

Fig. 1. Population dynamics of $P$. fluorescencs Q8r1-96Gm and its $d s b A$ mutant on the roots of wheat (cv. Penawawa) grown in Quincy virgin soil for six consecutive 2 week cycles. ( $a, b)$ Results of two independent experiments. (c) Results of a similar experiment with Q8r1-96Gm(pME6010) and the complemented mutant Q8r1-96dsbA(pME6010dsbA). Each strain was introduced into the soil to give a final density of approximately log 4 c.f.u. (g soil) ${ }^{-1}$ (cycle 0 ) in single inoculations and $\sim 0.5 \times 10^{4}$ c.f.u. (g soil) ${ }^{-1}$ of each strain in mixed inoculations as described in Methods. Mean values and standard deviations are presented. Means followed by the same letter are not significantly different $(P=0.05)$ according to Fisher's protected least significant difference test or the Kruskal-Wallis test $(P=0.05)$ (for cycles marked by an asterisk). 
the control were above $\log 8 \cdot 6$ c.f.u. $(\mathrm{g} \text { root })^{-1}$ in all six cycles, and population sizes did not differ (data not shown).

In order to assess the survival of the mutant in the absence of roots, soils after the final cycle of each colonization experiment were stored at $20{ }^{\circ} \mathrm{C}$ for 10 weeks, and then wheat was sown again. The mean population densities for two consecutive cycles are presented in Table 4 . Densities of the $d s b A$ mutant were significantly less than those of the wild-type in the rhizosphere of wheat sown in soil that had either single or mixed bacterial inoculations, suggesting that the mutant did not survive as well as the wild-type.

We complemented the Q8r1-96dsbA mutant with a wildtype copy of the gene in the low-copy-number plasmid pME6010, which is stably maintained in $P$. fluorescens $\mathrm{CHAO}$ in the absence of selection in the sugarbeet rhizosphere (Heeb et al., 2000). Our own experiments indicated that pME6010 is retained in Q8r1-96Gm colonizing the rhizosphere of wheat for at least 4 months (data not shown). Results of the rhizosphere colonization assays (Fig. 1c) and subsequent statistical analysis of mean colonization values after six cycles (data not shown) indicated that introduction of functional gene copies in trans indeed complemented the mutation in $d s b A$.

\section{DISCUSSION}

Successful root-colonizing rhizobacteria must establish and maintain themselves in the presence of a large, metabolically active microbial population supported by metabolites provided by the root. Considering the complexity of these interactions, it is not surprising that diverse bacterial traits have been implicated in root colonization by PGPR of different genera and species. These traits range from motility (de Weger et al., 1987), chemotaxis (Lugtenberg et al., 2001) and the presence of cell surface polysaccharides (Dekkers et al., 1998a), which may facilitate interactions with root surfaces, to prototrophy (Simons et al., 1997; de Weert et al., 2002), required for growth in the absence of preformed cellular building blocks; and the ability to sequester resources such as iron and oxygen (Camacho Carvajal, 2000), which may provide a competitive advantage over other rhizosphere micro-organisms. More recently, evidence of type III secretion genes in many Pseudomonas strains (Preston et al., 2001; Rainey, 1999, Mazurier et al., 2004; Rezzonico et al., 2004, 2005) and the preferential colonization of wheat and pea by different strains of DAPG-producing $P$. fluorescens (Landa et al., 2002b) led us to speculate that some PGPR may participate in more specialized interactions with the host, and that genes involved in these interactions may be among those broadly implicated in pathogen-host interactions. One such gene is $d s b A$, which influences interactions between $P$. aeruginosa and human, animal and plant hosts (Rahme et al., 1997, 2000) and contributes to pathogenicity in P. syringae pv. tomato and Erwinia chrysanthemi (Kloek et al., 2000; Shevchik et al., 1995). DsbA catalyses disulfide bond formation in the periplasm of Gram-negative bacteria, and $d s b A$ mutants exhibit a pleiotropic phenotype because the correct folding of many proteins is affected (Collet \& Bardwell, 2002). Among the effects of $d s b A$ mutations are deficiencies in pathogenicity and competitiveness associated with loss of motility and the inability to produce fimbriae and secrete exoproducts (Kloek et al., 2000; Shevchik et al., 1995; Dailey \& Berg, 1993). The fact that some of these traits are also associated with the ability of saprophytic pseudomonads to colonize and persist in the plant rhizosphere prompted us to investigate the role of $d s b A$ in root colonization.

We used a $d s b A$ probe from $P$. fluorescens SBW25 to identify $d s b A$-containing clones in a Q8r1-96 gene library. DNA sequence analysis revealed that the putative $d s b A$ gene from Q8r1-96 encodes a member of the thioredoxin superfamily containing the conserved dithiol-active site consensus motif $\mathrm{C}-\mathrm{P}-\mathrm{H}-\mathrm{C}$. The enzyme has a molecular mass similar to that

Table 4. Population densities of introduced wild-type and mutant strains in the rhizosphere of wheat sown in soil after 10 weeks storage

The survival of the strains was determined as the mean population density on roots of wheat plants after two cycles of growth following a 10 week fallow period as described in Methods. Mean population densities in log c.f.u. per g root (fresh weight) across two cycles except cycle 0 are presented; ND, none detected. Different lower-case letters indicate a statistically significant difference according to KruskalWallis all-pairwise comparisons test $(P=0 \cdot 05)$. Numbers in parentheses represent population density in $\log$ c.f.u. per g root (fresh weight) after cycle 6 (before storing soil for 10 weeks).

\begin{tabular}{|c|c|c|c|c|}
\hline \multirow[t]{2}{*}{ Expt } & \multirow[t]{2}{*}{ Strain } & \multicolumn{3}{|c|}{ Mean population density } \\
\hline & & Q8r1-96Gm & Mutant & $\begin{array}{l}\text { Q8r1-96Gm and } \\
\text { mutant at } 1: 1\end{array}$ \\
\hline \multirow[t]{2}{*}{1} & Q8r1-96Gm & $6 \cdot 0$ a $(6 \cdot 7)$ & $\mathrm{ND}$ & $5 \cdot 4 \mathrm{ab}(6 \cdot 0)$ \\
\hline & Q8r1-96dsbA & ND & $5 \cdot 0 \mathrm{bc}(5 \cdot 7)$ & $4 \cdot 3$ c $(5 \cdot 5)$ \\
\hline \multirow[t]{2}{*}{2} & Q8r1-96Gm & $6 \cdot 5$ a $(5 \cdot 9)$ & ND & $6 \cdot 3$ a $(6 \cdot 0)$ \\
\hline & Q8r1-96dsbA & ND & $5 \cdot 2 \mathrm{~b}(5 \cdot 9)$ & $4 \cdot 0 \mathrm{c}(3 \cdot 4)$ \\
\hline
\end{tabular}


of DsbA from other bacteria (approx. $20 \mathrm{kDa}$ ), has a wellconserved leader peptide for secretion via the Sec pathway, and is highly conserved ( $>70 \%$ identity at the amino acid level) relative to DsbA from $P$. syringae, $P$. putida, $P$. fluorescens and $P$. aeruginosa. Taken collectively, these results strongly suggest that the gene identified in strain Q8r1-96 is a true orthologue of $d s b A$ from $E$. coli.

The inactivation of $d s b A$ in $P$. fluorescens $\mathrm{Q} 8 \mathrm{r} 1-96$ resulted in a phenotype similar to that described for $d s b A$ mutants in other bacterial species. Like $d s b A$ mutants of $E$. coli (Dailey \& Berg, 1993) and P. syringae pv. tomato (Kloek et al., 2000), the $d s b A$ mutant of Q8r1-96 exhibited reduced motility and did not swarm. This is probably due to defective disulfide bond formation in FlgI, a component of the flagellar motor (Collet \& Bardwell, 2002; Dailey \& Berg, 1993). Like the $d s b A$ mutant of $P$. syringae pv. tomato (Kloek et al., 2000), that of Q8r1-96 also was less fluorescent than the wild-type on siderophore-inducing PsF agar (Table 3). In contrast to the $d s b A$ mutant of $P$. aeruginosa, which produced reduced clearing zones on skim milk agar (Malhotra et al., 2000), the Q8r1-96 mutant was unimpaired in the accumulation of extracellular protease and hydrogen cyanide. The latter indicates that the GacA/GacS regulatory circuitry, which coordinately regulates the production of secondary metabolites and exoprotease (Whistler et al., 1998), has not been disturbed in the $d s b A$ mutant. However, the Q8r1-96 mutant also produced elevated amounts of 2,4-DAPG and total phloroglucinol-related compounds and, as a result, was more inhibitory in vitro to G. graminis var. tritici than the wild-type. These and other changes, including those affecting colony morphology and nutrient utilization, presumably resulted from inactivation or functional alterations in periplasmic enzymes involved in secretion, nutrient uptake and the synthesis of cell envelope constituents. Whether the pleiotropic phenotype of the $d s b A$ mutation impacts on the ability of strain Q8r1-96 to function as a biological control agent in natural soil currently is under investigation.

We evaluated the contribution of $d s b A$ to the unique rootcolonizing ability of strain Q8r1-96Gm over several months in a natural field soil to which bacteria were added only once, after which a succession of wheat crops was grown. This approach allows for extended studies under controlled conditions in the presence of indigenous microbial populations. $P$. fluorescens Q8r1-96Gm and the $d s b A$ mutant were introduced into the soil either alone or in combination. When introduced separately, both strains colonized the rhizosphere similarly, whereas when the two were mixed, the mutant colonized the rhizosphere significantly less. We subscribe to the definition of root colonization proposed by Weller \& Thomashow (1994): 'the process whereby rhizobacteria introduced on seeds, vegetatively propagated plant parts or into the soil become distributed along roots growing in raw soil, multiply, and then survive for several weeks in the presence of indigenous soil microflora.' Based on this definition and our findings, we conclude that DsbA does not significantly contribute to the unique root-colonizing ability of Q8r1-96 even though the mutant was less fit in coinoculation studies. Indeed, it is not surprising that the mutant was less competitive in the presence of the wild-type because the wild-type is highly adapted to the root environment and almost any change would likely be disadvantageous. Apparently, however, the magnitude of the loss was not sufficient to have an impact on the mutant's ability to compete with the indigenous microflora.

Efforts over the past 25 years to establish the importance of chemotaxis and motility in root colonization have provided conflicting results. Motility has been found to contribute to the ability of bacteria to attach or become distributed over the root surface (de Weger et al., 1987; Catlow et al., 1990; Turnbull et al., 2001), particularly when studies are conducted in the absence of percolating water. On the other hand, the importance of active motility in soil has been questioned because flagella-mediated movement requires the presence of water films that become too thin to support motility when soil is drier than $-50 \mathrm{kPa}$ (Griffin \& Quail, 1968). Passive movement of bacteria on elongating roots was described by Howie et al. (1987), but downward percolation of water was shown to be more important for bacterial dispersal through the rhizosphere (Bahme \& Schroth, 1987). Our finding that the $d s b A$ mutant in this study was not impaired in root colonization may be due to our experimental conditions, which included regular watering of the plants. The water flow presumably contributed to the distribution of the bacteria along growing wheat roots, thus neutralizing the absence of motility.

Considering the range of exported proteins known to be acted upon by DsbA, and because a $d s b A$ mutation typically causes the same phenotype as a mutation in the gene encoding the protein acted upon, our results indicate that complex surface structures including flagella and fimbriae, previously studied in relation to root colonization, as well as the type III secretory apparatus, the importance of which is yet to be directly assessed, are unlikely to contribute significantly to the exceptional rhizosphere competence of $P$. fluorescens Q8r1-96. More generally, the relatively minor impact of the $d s b A$ mutation on root colonization by Q8r1-96 suggests that the unique host affinity of this strain does not depend on certain of the highly conserved virulence-related factors utilized by bacterial pathogens in their interactions with evolutionarily divergent hosts. Nonetheless, strain Q8r1-96 must, like pathogens, interact with and exploit nutrient resources provided by its host, and it remains to be determined whether the functional similarities associated with these processes will share a common underlying genetic basis.

\section{ACKNOWLEDGEMENTS}

This work was supported by the US Department of Agriculture, National Research Initiative, Competitive Grants Program (grants 2003-35319-13800 and 2003-35107-13777). We thank K. Hansen, M. Young Son and J. Mitchell for technical assistance. 


\section{REFERENCES}

Ausubel, F. M., Brent, R., Kingston, R. E., Moore, D. D., Seidman, J. G., Smith, J. A. \& Struhl, K. (1995). Short Protocols in Molecular Biology, 3rd edn. New York: Wiley.

Bahme, J. B. \& Schroth, M. N. (1987). Spatial-temporal colonization patterns of a rhizobacterium on underground organs of potato. Phytopathology 79, 1093-1101.

Bakker, A. W. \& Schippers, B. (1987). Microbial cyanide production in the rhizosphere in relation to potato yield reduction and Pseudomonas spp. mediated plant growth stimulation. Soil Biol Biochem 19, 451-457.

Bangera, M. G. \& Thomashow, L. S. (1999). Identification and characterization of a gene cluster for synthesis of the polyketide antibiotic 2,4-diacetylphloroglucinol from Pseudomonas fluorescens Q2-87. J Bacteriol 181, 3155-3163.

Bardwell, J. C. A., McGovern, K. \& Beckwith, J. (1991). Identification of a protein required for disulphide bond formation in vivo. Cell 67, 581-589.

Bauer, D. W. \& Collmer, A. (1997). Molecular cloning, characterization, and mutagenesis of a pel gene from Pseudomonas syringae pv. lachrymans encoding a member of the Erwinia chrysenthemi PelADE family of pectate lyases. Mol Plant Microbe Interact 10, 369-379.

Bendtsen, J. D., Nielsen, H., von Heijne, G. \& Brunak, S. (2004). Improved prediction of signal peptides: SignalP 3.0. J Mol Biol 340, 783-795.

Birren, B., Green, E. D., Klapholz, S., Myers, M. R., Riethman, H. \& Roskams, J. (1999). Genome Analysis: a Laboratory Manual, vol. 3, Cloning Systems. Cold Spring Harbor, NY: Cold Spring Harbor Laboratory.

Bonsall, R. F., Weller, D. M. \& Thomashow, L. S. (1997). Quantification of 2·4-diacetylphloroglucinol produced by fluorescent Pseudomonas spp. in vitro and in the rhizosphere of wheat. Appl Environ Microbiol 63, 951-955.

Bull, C. T., Weller, D. M. \& Thomashow, L. S. (1991). Relationship between root colonization and suppression of Gaeumannomyces graminis var. tritici by Pseudomonas fluorescens strain 2-79. Phytopathology 81, 954-959.

Camacho Carvajal, M. M. (2000). Molecular characterization of the role of Type 4 pili, NADH-I and PyrR in rhizosphere colonization of Pseudomonas fluorescens WCS365. PhD Dissertation, Utrecht University, The Netherlands.

Catlow, H. J., Glenn, A. R. \& Dilworth, M. J. (1990). The use of transposon-induced non-motile mutants in assessing the significance of motility of Rhizobium leguminosarum biovar trifoli for movement in soils. Soil Biol Biochem 22, 331-336.

Collet, J. F. \& Bardwell, J. C. (2002). Oxidative protein folding in bacteria. Mol Microbiol 44, 1-8.

Dailey, F. E. \& Berg, H. C. (1993). Mutants in disulfide bond formation that disrupt flagellar assembly in Escherichia coli. Proc Natl Acad Sci U S A 90, 1043-1047.

Dekkers, L. C., van der Bij, A. J., Mulders, I. H. M., Phoelich, C. C., Wentwoord, R. A. R., Glandorf, D. C. M., Wijffelman, C. A. \& Lugtenberg, B. J. J. (1998a). Role of the O-antigen of lipopolysaccharide, and possible roles of growth rate and of $\mathrm{NADH}$ : ubiquinone oxidoreductase (nuo) in competitive tomato root-tip colonization by Pseudomonas fluorescens WCS365. Mol Plant Microbe Interact 11, 763-771.

Dekkers, L. C., Phoelich, C. C., van der Fits, L. \& Lugtenberg, B. J. J. (1998b). A site-specific recombinase is required for competitive root colonization by Pseudomonas fluorescens WCS365. Proc Natl Acad Sci U S A 95, 7051-7056.
Dekkers, L. C., Bloemendaal, C. J. P., de Weger, L. A., Wijffelman, C. A., Spaink, H. P. \& Lugtenberg, B. J. J. (1998c). A two-component system plays an important role in the root-colonizing ability of Pseudomonas fluorescens strain WCS365. Mol Plant Microbe Interact 11, 45-56.

Dekkers, L. C., Mulders, I. H. M., Phoelich, C. C., Chin-a-Woeng, T. F. C., Wijfjes, A. H. M. \& Lugtenberg, B. J. J. (2000). The sss colonization gene of the tomato-Fusarium oxysporum f.sp. radicislycopersici biocontrol strain Pseudomonas fluorescens WCS365 can improve root colonization of other wild-type Pseudomonas spp. bacteria. Mol Plant Microbe Interact 13, 1177-1183.

de Weert, S., Vermeiren, H., Mulders, I. H. M., Kuiper, I., Hendrickx, N., Bloemberg, G. V., Vanderleyden, J., De Mot, R. \& Lugtenberg, B. J. J. (2002). Flagella-driven chemotaxis towards exudates components is an important trait for tomato root colonization by Pseudomonas fluorescens. Mol Plant Microbe Interact 15, 1173-1180.

de Weger, L. A., Van der Vlugt, C. I. M., Wijfjes, A. H. M. M., Bakker, P. A. H. B., Schippers, B. \& Lugtenberg, B. J. J. (1987). Flagella of a plant-growth-stimulating Pseudomonas fluorescens strain are required for colonization of potato roots. J Bacteriol 169, 2769-2773.

Duffy, B. K. \& Défago, G. (1997). Zinc improves biocontrol of Fusarium crown and root rot of tomato by Pseudomonas fluorescens and represses the production of pathogen metabolites inhibitory to bacterial antibiotic biosynthesis. Phytopathology 87, 1250-1257.

Enderle, P. J. \& Farwell, M. A. (1998). Electroporation of freshly plated Escherichia coli and Pseudomonas aeruginosa cells. BioTechniques 25, 954-958.

Griffin, D. M. \& Quail, G. (1968). Movement of bacteria in moist particulate systems. Aust J Biol Sci 21, 579-582.

Heeb, S., Itoh, Y., Nishijyo, T., Schnider, U., Keel, C., Wade, J., Walsh, U., O'Gara, F. \& Haas, D. (2000). Small, stable shuttle vectors based on the minimal pVS1 replicon for use in gram-negative, plantassociated bacteria. Mol Plant Microbe Interact 13, 232-237.

House, B. L., Mortimer, M. W. \& Kahn, M. L. (2004). New recombination methods for Sinorhizobium meliloti genetics. Appl Environ Microbiol 70, 2806-2815.

Howie, W. J., Cook, R. J. \& Weller, D. M. (1987). Effects of soil matric potential and cell motility on wheat root colonization by fluorescent Pseudomonas suppressive to take all. Phytopathology 77, 286-292.

Hu, S. H., Peek, J. A., Rattigan, E., Taylor, R. K. \& Martin, J. L. (1997). Structure of TcpG, the $d s b A$ protein folding catalyst form Vibrio cholerae. J Mol Biol 268, 137-146.

Jackson, M. W. \& Plano, G. V. (1999). DsbA is required for stable expression of outer membrane protein $\mathrm{YscC}$ and for efficient secretion in Yersinia pestis. J Bacteriol 181, 5126-5130.

Keel, C., Schnider, U., Maurhofer, M., Voisard, C., Laville, J., Burger, U., Wirthner, P., Haas, D. \& Défago, G. (1992). Suppression of root diseases by Pseudomonas fluorescens CHA0: importance of the bacterial secondary metabolite 2,4-diacetylphloroglucinol. Mol Plant Microbe Interact 5, 4-13.

King, E. O., Ward, M. K. \& Raney, D. (1954). Two simple media for the demonstration of pyocyanin and fluorescein. J Lab Clin Med 44, 301-307.

Kloek, A. P., Brooks, D. M. \& Kunkel, B. N. (2000). A $d s b$ A mutant Pseudomonas syringae exhibits reduced virulence and partial impairment of type III secretion. Mol Plant Pathol 1, 139-150.

Landa, B. B., de Werd, H. A. E., McSpadden Gardener, B. B. \& Weller, D. M. (2002a). Comparison of three methods for monitoring populations of different genotypes of 2,4-diacetylphloroglucinolproducing Pseudomonas fluorescens in the rhizosphere. Phytopathology 92, 129-137. 
Landa, B. B., Mavrodi, O. V., Raaijmakers, J., McSpadden Gardener, B. B., Thomashow, L. S. \& Weller, D. M. (2002b). Differential ability of genotypes of 2,4-diacetylphloroglucinol-producing Pseudomonas fluorescens strains to colonize the roots of pea plants. Appl Environ Microbiol 68, 3226-3237.

Landa, B. B., Mavrodi, D. V., Raaijmakers, J., Thomashow, L. S. \& Weller, D. M. (2003). Interactions between strains of 2,4-diacetylphloroglucinol-producing Pseudomonas fluorescens strains in the rhizosphere of wheat. Phytopathology 93, 982-994.

Lugtenberg, B. J. J., Dekkers, L. C. \& Bloemberg, G. V. (2001). Molecular determinants of rhizosphere colonization by Pseudomonas. Annu Rev Phytopathol 39, 461-490.

Malhotra, S., Silo-Suh, L. A., Mathee, K. \& Ohman, D. E. (2000). Proteome analysis of the effect of mucoid conversation on global protein expression in Pseudomonas aeruginosa strain PAO1 shows induction of the disulfide bond isomerase, DsbA. J Bacteriol 182, 6999-7006.

Mavrodi, D. V., Bonsall, R. F., Delaney, S. M., Soule, M. J., Phillips, G. \& Thomashow, L. S. (2001). Functional analysis of genes for biosynthesis of pyocyanin and phenazine-1-carboxamide from Pseudomonas aeruginosa PAO1. J Bacteriol 183, 6454-6465.

Mavrodi, O. V. (2004). Phenotypic, genotypic and colonization properties of 2,4-diacetylphloroglucinol-producing fluorescent Pseudomonas spp. isolated from roots of wheat. $\mathrm{PhD}$ dissertation, Washington State University, Pullman, WA.

Mavrodi, O. V., McSpadden Gardener, B. B., Mavrodi, D. V., Weller, D. M. \& Thomashow, L. S. (2001). Genetic diversity of phlD from 2,4-diacetylphloroglucinol-producing fluorescent Pseudomonas spp. Phytopathology 91, 35-43.

Mazurier, S., Lemunier, M., Siblot, S., Mougel, C. \& Lemanceau, P. (2004). Distribution and diversity of type III secretion system-like genes in saprophytic and phytopathogenic fluorescent pseudomonads. FEMS Microbial Ecol 49, 455-467.

McSpadden Gardener, B. B. \& Weller, D. M. (2001). Changes in populations of rhizosphere bacteria associated with take-all disease of wheat. Appl Environ Microbiol 67, 4414-4425.

McSpadden Gardener, B. B., Schroeder, K. L., Kalloger, S. E., Raaijmakers, J. M., Thomashow, L. S. \& Weller, D. M. (2000). Genotypic and phenotypic diversity of phlD-containing Pseudomonas isolated from the rhizosphere of wheat. Appl Environ Microbiol 66, 1939-1946.

McSpadden Gardener, B. B., Mavrodi, D. V., Thomashow, L. S. \& Weller, D. M. (2001). A rapid PCR-based assay characterizing rhizosphere populations of 2,4-DAPG-producing bacteria. Phytopathology 91, 44-54.

Pagni, M., loannidis, V., Cerutti, L., Zahn-Zabal, M., Jongeneel, C. V. \& Falquet, L. (2004). Myhits: a new interactive resource for protein annotation and domain identification. Nucleic Acids Res 32, (Web Server issue) W332-335.

Preston, G. M., Bertrand, N. \& Rainey, P. B. (2001). Type III secretion in plant growth-promoting Pseudomonas fluorescens SBW25. Mol Microbiol 41, 999-1014.

Raaijmakers, J. M. \& Weller, D. M. (2001). Exploiting the genetic diversity of Pseudomonas spp: characterization of superior colonizing P. fluorescens strain Q8r1-96. Appl Environ Microbiol 67, 2545-2554.

Rahme, L. G., Tan, M.-W., Le, L., Wong, S. M., Tompkins, R. G., Calderwood, S. B. \& Ausubel, F. M. (1997). Use of model plant hosts to identify Pseudomonas aeruginosa virulence factors. Proc Natl Acad Sci U S A 94, 13245-13250.

Rahme, L. G., Ausubel, F. M., Cao, H. \& 9 other authors (2000). Plants and animals share functionally common bacterial virulence factors. Proc Natl Acad Sci U S A 97, 8815-8821.
Rainey, P. B. (1999). Adaptation of Pseudomonas fluorescens to the plant rhizosphere. Environ Microbiol 1, 243-257.

Rezzonico, F., Défago, G. \& Moënne-Loccoz, Y. (2004). Comparison of ATP-encoding type III secretion system $h r c N$ genes in biocontrol fluorescent pseudomonas and in phytopathogenic proteobacteria. Appl Environ Microbiol 70, 5119-5131.

Rezzonico, F., Binder, C., Défago, G. \& Moënne-Loccoz, Y. (2005). The type III secretion system of biocontrol Pseudomonas fluorescens KD targets the phytopathogenic chromista Pythium ultimum and promotes cucumber protection. Mol Plant Microbe Interact 18, 991-1001.

Sacherer, P., Défago, G. \& Haas, D. (1994). Extracellular protease and phospholipase $\mathrm{C}$ are controlled by the global regulatory gene gacA in the biocontrol strain Pseudomonas fluorescens CHAO. FEMS Microbiol Lett 116, 115-160.

Schweizer, H. P. (1992). Allelic exchange in Pseudomonas aeruginosa using novel ColE1-type vectors and a family of cassettes containing portable oriT and the counter-selectable Bacillus subtillis sacB marker. Mol Microbiol 6, 1195-1204.

Schwyn, B. \& Neilands, J. B. (1987). Universal chemical assay for the detection and determination of siderophores. Anal Biochem 160 , 47-56.

Shanahan, P., O'Sullivan, D. J., Simpson, P., Glennon, J. D. \& O'Gara, F. (1992). Isolation of 2,4-diacetylphlorogluciol from a fluorescent pseudomonad and investigation of physiological parameters influencing its production. Appl Environ Microbiol 58, 353-358.

Shevchik, V. E., Bortoli-German, I., Robert-Baudouy, J., Robinet, S., Barras, F. \& Condemine, G. (1995). Differential effect of $d s b A$ and $d s b C$ mutations on extracellular enzyme secretion in Erwinia chrysanthemi. Mol Microbiol 16, 745-753.

Simons, M., Permentier, H. P., de Weger, L. A., Wijffelman, C. A. \& Lugtenberg, B. J. J. (1997). Amino acid synthesis is necessary for tomato root colonization by Pseudomonas fluorescens strain WCS365. Mol Plant Microbe Interact 10, 102-106.

Tamietti, G., Ferraris, L., Matta, A. \& Abbattista Gentile, I. (1993). Physiological responses of tomato plants grown in Fusarium suppressive soil. J Phytopathol 138, 66-76.

Turnbull, G. A., Morgan, J. A. W., Whipps, J. M. \& Saunders, J. R. (2001). The role of bacterial motility in the survival and spread of Pseudomonas fluorescens in soil in the attachment and colonization of wheat roots. FEMS Microbiol Ecol 36, 21-31.

Urban, A., Leipelt, M., Eggert, T. \& Jaeger, K.-E. (2001). DsbA and DsbC affect extracellular enzyme formation in Pseudomonas aeruginosa. J Bacteriol 183, 587-596.

Validov, S., Mavrodi, O. V., De La Fuente, L., Boronin, A., Weller, D. M., Thomashow, L. S. \& Mavrodi, D. V. (2005). Antagonistic activity among phlD-containing fluorescent Pseudomonas spp. FEMS Microbiol Lett 242, 249-256.

Watarai, M., Tobe, T., Yoshikawa, M. \& Sasakawa, C. (1995). Disulfide oxidoreductase activity of Shigella flexneri is required for release of Ipa proteins and invasion of the epithelial cells. Proc Natl Acad Sci U S A 92, 4927-4931.

Weller, D. M. (1988). Biological control of soilborne pathogens in the rhizosphere with bacteria. Annu Rev Phytopathol 26, 379-407.

Weller, D. M. \& Thomashow, L. S. (1994). Current challenges in introducing beneficial microorganisms into the rhizosphere. In Molecular Ecology of Rhizosphere Microorganisms: Biotechnology and Release of GMOs, pp. 1-18. Edited by F. O'Gara, D. N. Dowling \& B. Boesten. New York: VCH.

Whistler, C. A., Corbell, N. A., Sarniguet, A., Ream, W. \& Loper, J. E. (1998). The two-component regulators GacS and GacA influence accumulation of the stationary-phase sigma factor $\sigma^{54}$ and the stress response in Pseudomonas fluorescens Pf-5. J Bacteriol 180, 6635-6641. 